\title{
Update on the importance of parenchymal patterns and breast cancer risk
}

\author{
J. Ding, R. Warren \\ Department of Radiology, University of Cambridge, Addenbrooke's Hospital, Cambridge, UK.
}

\begin{abstract}
Mammographic density is a well-documented independent risk factor for breast cancer. Measurements of density come in various forms, ranging from qualitative descriptions to quantitative assessments or a combination of both. The different means of examining density lead to variations in density-risk relationship. Currently there is no consensus on which method is preferable. The interrelation of mammographic density with other risk factors is crucial to density-risk assessments, since each of these risk factors can influence density on its own. Mammographic density can be modified through hormonal and chemical means, which can have important implications on mammographic sensitivity, accuracy in cancer diagnosis and cancer prevention.
\end{abstract}

Keywords: Mammographic density; Parenchymal patterns; Breast cancer risk

\section{Introduction}

Screening mammography is the most widely used method for early diagnosis of breast cancer. A breast can be divided into two major components based on its mammographic appearance: fibroglandular tissue and fat. The mammographic appearance of healthy breasts represents a continuum ranging from ones with predominantly fatty tissue to those with mainly fibroglandular tissue. Fibroglandular tissue is a mixture composed of fibrous connective tissue (the stroma), and glandular tissue, which includes the epithelial cells that line the ducts. Fat is more radiolucent than fibroglandular tissue and therefore it appears darker in mammograms. It is the bright regions (due to greater attenuation of X-rays) associated with fibroglandular tissue that fit today's loose and commonly accepted definition of 'mammographic density'.

Correspondence to: R. Warren, Cambridge Breast Unit, Addenbrooke's Hospital, Cambridge, CB2 2QQ, UK. E-mail: rmlw2@cam.ac.uk

Publication date 17/12/04

BCO/222/2004/FO

\section{Methods for assessing mammographic density}

The different methods for estimating mammographic density have been subjected to analyses by several literatures [1-5]. Methods for measuring mammographic density can be divided into two broad categories. First, density can be evaluated by assessing a variety of features of the breast, which includes the percentage of the breast occupied with dense regions as well as characteristics of densities such as texture and shape. In 1976, Wolfe developed a four-category classification scheme (N1, P1, P2 and DY) to group parenchyma into different degrees of risk, based on the proportion of breast with dense area and other morphological features of the breast such as prominent ducts and dysplasia [6]. A less frequently used qualitative classification method, Tabar's scheme was based on anatomical features of the breast together with how they related to the supposed pathology [7]. In 1987, Saftlas and Szklo reviewed all the studies that used the Wolfe criteria [8]. They concluded that these studies do support the relationship between Wolfe's classification and cancer 
risk, but that inconsistencies in applying the parenchymal pattern classification lead to problems with observer subjectivity [8]. To address this limitation, researchers attempted to quantify, rather than qualify, the degree of mammographic density. The second type of density estimation involves assessing the extent of fibroglandular densities of the breast without taking into account types of densities and morphological features of the breast. One of the most widely used scheme was devised by Boyd, whose visual method involved allocating cases to one of the six categories of estimated proportions of density on the mammogram [4]. Several attempts have been made to apply computer methods to measurements of density, with Boyd and Yaffe's interactive threshold program being the most well known [9]. Analyses comparing the actual volume of fibroglandular and fatty tissue measured by magnetic resonance imaging (MRI) to the percentage area of density estimated from mammograms demonstrated that the 2D measurements did not truly represent the dense area and tend to overestimate the amount of density [10]. Recent developments in this field explored automated methods that measure density volumetrically. For this, the 3D of the breast (thickness) must either be recorded at the time of the mammogram or estimated with a high level of accuracy. Several such methods are in development of different groups, each applying their own methodology.

\section{Mammographic density and breast cancer risk}

In 1976, Wolfe proposed a positive association between parenchymal patterns and breast cancer risk [6]. Since then, many researchers investigated Wolfe's original work and showed strong riskpattern relationships of 4-6-fold increase in risk for women with high-risk patterns [11,2]. However, none was able to reproduce Wolfe's original results demonstrating a 37-fold relative risk [6]. In general, the P2DY group is at an elevated risk compared to the low-risk N1P1 group $[13,4]$. There has been considerable controversy over whether DY or P2 is the highest risk category. Age seems to be a factor in this debate, since the DY pattern sometimes regresses to less dense patterns after 40 years of age [15]. This dynamic regression process in Wolfe's patterns leads to difficulties in determining which of the two patterns is the highest risk.

Studies investigating quantitative density measurements also obtained stepwise increases in percent density as being associated with higher risks of developing breast cancer. Women with more than $75 \%$ density have been shown to have 5-6 times higher risk for breast cancer compared to those with fatty breasts
$[2,16,17]$. Most studies found higher breast cancer risk for percent density compared to Wolfe's classification $[2,14,17]$. Several studies evaluated the two methods and showed that percent density provided more information than Wolfe's parenchymal patterns. Once percent density is taken into account, no new information is given from assessing Wolfe's patterns $[1,2,5]$.

Increased mammographic density was found to be associated with high-grade tumours and ductal carcinoma in situ (DCIS) [18]. Tumours large in size were shown to be associated with the densest pattern. This was due to a combination of impaired sensitivity and tumours with accelerated growth [19]. Tumours detected in the interval after a negative screen (interval cancers) display these characteristics. An important consequence of mammographic density is the impairment of the effectiveness of mammography screening for breast cancer. This is compounded by the use of hormone replacement therapy (HRT) which increases density [20]. It is also important when young women at elevated risk are screened, since the various causes of elevated risk are associated with dense patterns [21].

\section{Mammographic density and known risk factors for breast cancer}

Mammographic density is an independent risk factor for breast cancer. Although age, body mass index (BMI), weight, parity, menopausal status, age at first birth, parity, hormonal agents and family history all influence density, breast density has been consistently shown to be an independent risk factor after adjusting for most of these variables [22]. The risk of breast cancer for women with increased density is greater than that for most traditional risk factors such as nulliparity and early menarchy [22]. It is also associated with some lifestyle factors which affect risk, such as diet $[23,24]$ and smoking [25].

\section{Mammographic density and BMI}

Obesity is a known risk factor for breast cancer. Women with high-risk patterns or high densities more likely have a lean body build $[2,26]$. That is, the relationship between BMI and breast density patterns is inverse. This relationship is mainly due to the fact that women who weigh more also have proportionally more fat in their breasts, resulting in a low percentage of density [27]. Obesity is a risk factor with an association with breast density that goes contrary to the gradient of risk for breast cancer [28]. Consequently, the calculations for density-risk association must be adjusted for BMI to give a true reading. Indeed, evidence showed that the relationship between high risk and patterns was strengthened when adjusted for weight and height $[2,26]$. 


\section{Interventions that change mammographic density}

The recognition that mammographic density is associated with risk of developing breast cancer brings forth the idea that modifying density can subsequently change a woman's cancer risk. HRT are believed to preserve or increase mammographic density by slowing normal breast involution $[29,30]$. Sala showed an even stronger correlation when the duration of HRT was prolonged and started before menopause [31]. There has been some suggestion regarding the worth of women ceasing to take HRT prior to their mammography in order to improve sensitivity and specificity, but there is no experimental evidence on which to justify this clinical practice. On the contrary, tamoxifen has the effect of reducing mammographic density $[32,33]$. This has the consequence of improving the sensitivity of post-treatment mammographic surveillance.

Furthermore, mammographic density can be used as an accessible method for monitoring breast cancer risk $[12,34]$. That is, mammographic density may be used to monitor the intervention when a high-risk woman changes her diet, exercise routine or begins to take pharmacological agents such as tamoxifen in view to change her propensity to develop breast cancer [35].

\section{Masking effect: an explanation for the density-risk relationship}

Egan and Mosteller proposed the masking hypothesis to explain the relationship between breast density and breast cancer risk [36]. This hypothesis states that because tumours are more difficult to be detected in dense breast mammograms, prevalence cancers are likely to be missed or obscured at the first screening among women with dense breast tissue [36]. As a result, density may not be a risk factor but a mask for breast cancer. van Gils carried out a small study to examine the possible effect of masking on the relationship between breast density and cancer risk. Although masking bias does occur, its effects are small and short-lived [37]. This hypothesis was also examined by Couto and she concluded that there was an intrinsic relationship between density, and large- and high-grade tumours separate from masking [38].

\section{What is the effect of inheritance on dense patterns?}

Dense patterns predominate in women with a family history of breast cancer [39-42]. The detailed relationship has been studied in a large population of mono and dizygotic twins and from this it has been estimated that genetic factors account for about $60 \%$ with the remaining percentage being accounted for by other factors, which may be open to change. These relationships are being further studied in various settings including women with known familial gene mutations and in sporadic cancer. This will yield more information on not only the inheritance of density but also the understanding of genetic factors, possibly lower penetrance genes involved in sporadic cancer.

\section{Conclusion}

Mammographic density is an important tool used to estimate breast cancer risk. Further explorations into developing more accurate and practical automated methods of assessing density can open a path for extensive use of this risk indicator in both clinical and research environments.

\section{References}

1. Saftlas AF, Hoover RN, Brinton LA, et al. Mammographic densities and risk of breast cancer. Cancer 1991; 67: 2833-2838.

2. Byrne C, Schairer C, Wolfe J, et al. Mammographic features and breast cancer risk: effects with time, age, and menopause status. J Natl Cancer Inst 1995; 87: 1622-1629.

3. Thomas DB, Carter RA, Bush Jr WH, et al. Risk of subsequent breast cancer in relation to characteristics of screening mammograms for women less than 50 years of age. Cancer Epidemiol Biomarkers Prev 2002; 11: 565-571.

4. Warner E, Lockwood G, Tritchler D, Boyd NF. The risk of breast cancer associated with mammographic parenchymal patterns: a meta-analysis of the published literature to examine the effect of method of classification. Cancer Detect Prev 1992; 16: 67-72.

5. Brisson J, Diorio C, Masse B. Wolfe's parenchymal pattern and percentage of the breast with mammographic densities: redundant or complementary classifications? Cancer Epidemiol Biomarkers Prev 2003; 12: 728-732.

6. Wolfe JN. Breast patterns as an index of risk for developing breast cancer. Am J Roentgenol 1976; 126: 1130-1137.

7. Gram IT, Funkhouser E, Tabar L. The Tabar classification of mammographic parenchymal patterns. Eur $J$ Radiol 1997; 24: 131-136.

8. Saftlas AF, Szklo M. Mammographic parenchymal patterns and breast cancer risk. Epidemiol Rev 1987; 9: 146-174.

9. Byng JW, Yaffe MJ, Lockwood GA, Little LE, Tritchler DL, Boyd NF. Automated analysis of mammographic densities and breast carcinoma risk. Cancer 1997; 80: 66-74.

10. Lee NA, Rusinek H, Weinreb J, et al. Fatty and fibroglandular tissue volumes in the breasts of women 20-83 years old: comparison of X-ray mammography and computer-assisted MR imaging. Am J Roentgenol 1997; 168: 501-506.

11. Byrne C. Studying mammographic density: implications for understanding breast cancer. J Natl Cancer Inst 1997; 89: 531-533. 
12. Boyd NF, Lockwood GA, Byng JW, Tritchler DL, Yaffe MJ. Mammographic densities and breast cancer risk. Cancer Epidemiol Biomarkers Prev 1998; 7: 1133-1144.

13. Krook PM, Carlile T, Bush W, Hall MH. Mammographic parenchymal patterns as a risk indicator for prevalent and incident cancer. Cancer 1978; 41: 1093-1097.

14. Brisson J, Verreault R, Morrison AS, Tennina S, Meyer F. Diet, mammographic features of breast tissue, and breast cancer risk. Am J Epidemiol 1989; 130: 14-24.

15. Flook D, Gilhome RW, Harman J, Gravelle IH, Webster DJT. Changes in Wolfe mammographic patterns with aging. Br J Radiol 1987; 60: 455-456.

16. Boyd NF, Byng JW, Jong RA, et al. Quantitative classification of mammographic densities and breast cancer risk: results from the Canadian National Breast Screening Study. J Natl Cancer Inst 1995; 87: 670-675.

17. Boyd NF, O'Sullivan B, Campbell JE, et al. Mammographic signs as risk factors for breast cancer. Br J Cancer 1982; 45: 185-193.

18. Sala E, Solomon L, Warren R, et al. Size, node status and grade of breast tumours: association with mammographic parenchymal patterns. Eur Radiol 2000; 10: 157-161.

19. Sala E, Warren R, McCann J, Duffy S, Luben R, Day N. Mammographic parenchymal patterns and breast cancer natural history - a case-control study. Acta Oncol 2001; 40: 461-465.

20. Banks E. Hormone replacement therapy and the sensitivity and specificity of breast cancer screening: a review. J Med Screen 2001; 8: 29-34.

21. Warren R. Screening women at high risk of breast cancer on the basis of evidence. Eur J Radiol 2001; 39: 50-59.

22. Harvey JA, Bovbjerg VE. Quantitative assessment of mammographic breast density: relationship with breast cancer risk. Radiology 2004; 23: 29-41.

23. Sala E, Warren R, Duffy S, Welch A, Luben R, Day N. High risk mammographic parenchymal patterns and diet: a case-control study. $\mathrm{Br} J$ Cancer 2000; 83: 121-126.

24. Maskarinec G, Lyu LC, Meng L, Theriault A, Ursin G. Determinants of mammographic densities among women of Asian, Native Hawaiian, and Caucasian ancestry. Ethn Dis 2001; 11: 44-50.

25. Warwick J, Pinney E, Warren RM, et al. Breast density and breast cancer risk factors in a high-risk population. Breast 2003; 12: 10-16.

26. Brisson J, Morrison AS, Kopans DB, et al. Height and weight, mammographic features of breast tissue, and breast cancer risk. Am J Epidemiol 1984; 119: 371-381.

27. Boyd NF, Lockwood GA, Byng JW, Little LE, Yaffe MJ, Tritchler DL. The relationship of anthropometric measures to radiological features of the breast in premenopausal women. Br J Cancer 1998; 78: 1233-1238.
28. Day N, Warren R. Mammographic screening and mammographic patterns. Breast Cancer Res 2000; 2: 247-251.

29. Leung W, Goldberg F, Zee B, Sterns E. Mammographic density in women on postmenopausal hormone replacement therapy. Surgery 1997; 122: 669-674.

30. Lam PB, Vacek PM, Geller BM, Muss HB. The association of increased weight, body mass index, and tissue density with the risk of breast carcinoma in Vermont. Cancer 2000; 89: 369-375.

31. Sala E, Warren R, McCann J, Duffy S, Luben R, Day N. High-risk mammographic parenchymal patterns, hormone replacement therapy and other risk factors: a casecontrol study. Int J Epidemiol 2000; 29: 629-636.

32. Atkinson C, Warren R, Bingham SA, Day NE. Mammographic patterns as a predictive biomarker of breast cancer risk: effect of tamoxifen. Cancer Epidemiol Biomarkers Prev 1999; 8: 863-866.

33. Brisson J, Brisson B, Cote G, Maunsell E, Berube S, Robert J. Tamoxifen and mammographic breast densities. Cancer Epidemiol Biomarkers Prev 2000; 9: 911-915.

34. Boyd NF, Martin LJ, Stone J, Greenberg C, Minkin S, Yaffe MJ. Mammographic densities as a marker of human breast cancer risk and their use in chemoprevention. Curr Oncol Rep 2001; 3: 314-321.

35. Dirx MJ, Voorrips LE, Goldbohm RA, van den Brandt PA. Baseline recreational physical activity, history of sports participation, and postmenopausal breast carcinoma risk in the Netherlands Cohort Study. Cancer 2001; 92: 1638-1649.

36. Egan RL, Mosteller RC. Breast cancer mammography patterns. Cancer 1977; 40: 2087-2090.

37. van Gils $\mathrm{CH}$, Otten JD, Verbeek AL, Hendriks JH. Mammographic breast density and risk of breast cancer: masking bias or causality? Eur J Epidemiol 1998; 14: 315-320.

38. Couto E, Harrison D, Duffy S, et al. Estimation of disease progression parameters from case-control data: application to mammographic patterns and breast cancer natural history. J Epidemiol Biostat 2001; 6: 235-242.

39. Boyd NF, Lockwood GA, Martin LJ, et al. Mammographic densities and risk of breast cancer among subjects with a family history of this disease. J Natl Cancer Inst 1999; 91: 1404-1408.

40. Kerlikowske K, Grady D, Barclay J, Sickles EA, Ernster V. Effect of age, breast density, and family history on the sensitivity of first screening mammography. J Am Med Assoc 1996; 276: 33-38.

41. Ziv E, Shepherd J, Smith-Bindman R, Kerlikowske K. Mammographic breast density and family history of breast cancer. J Natl Cancer Inst 2003; 95: 556-558.

42. Vachon CM, Sellers TA, Vierkant RA, Wu FF, Brandt KR. Case-control study of increased mammographic breast density response to hormone replacement therapy. Cancer Epidemiol Biomarkers Prev 2002; 11:1382-1388. 